\title{
The effects of bilateral hippocampal lesions on two-way active avoidance in the guinea pig'
}

LEONARD C. IRELAND, WILLIAM N. HAYES, and RONALD E. SCHAUB, ${ }^{2}$ State University of New York at Buffalo, N. Y. 14214

Guinea pigs (Cavia porcellus) suffering bilateral hippocampal destruction, cortical animals suffering destruction of the posterolateral neocortex, and normal animals were trained over a six-day period in a two-way shuttle-box avoidance problem. Hippocampectomized Ss reached the learning criterion more quickly, showed lower latencies, and displayed more intertrial activity than normal and cortical Ss. Cortical Ss made more spontaneous crosses than normal Ss.

Evonic \& Brimer (1967) reported that guinea pigs on a standard training schedule are virtually unable to learn a two-way active avoidance response. To explain this deficit, they suggest that in the guinea pig, fear responses may be "readily conditioned to any stable aspect of the avoidance situation" and that these fear reactions may produce "freezing behavior" which interferes with learning the task. Bilateral lesions of the hippocampus in rats have been reported to reduce such freezing behavior (Green, Beatty, \& Schwartzbaum, 1967) and to greatly facilitate learning of a two-way avoidance task (Green et al, 1967; Isaacson, Douglas, \& Moore, 1961; Olton \& Isaacson, in press). The purpose of the present study was to determine the effects of bilateral hippocampal lesions on the freezing behavior and avoidance performance of guinea pigs in a two-way active avoidance situation.

\section{METHOD}

The Ss were 15 experimentally naive male guinea pigs (Cavia porcellus) weighing from $600-700 \mathrm{~g}$ at the time of surgery. Five Ss received bilateral hippocampal lesions, five received lesions of the cortex overlying the hippocampus, and five served as unoperated controls. All operations were performed under barbiturate anesthesia. In the hippocampally damaged group, the skull was opened and the cortex overlying the hippocampus was removed by aspiration. In the cortically damaged group, the hippocampus was similarly exposed but left intact. All wounds were packed with Gelfoam and the scalps closed with surgical wound clips. All Ss received sulfa in their drinking water for 10 days prior to surgery and during the course of the experiment. All lesioned animals were allowed 14 days to recover before the start of the experiment.

After the experiment, Ss with lesions were sacrificed with sodium pentobarbital, intracardially perfused with $10 \%$ formalin, and the brains removed. Frozen serial sections between $25-30 \mu$ were made throughout the damaged areas. Histological examination of the brains revealed extensive bilateral lesions involving the dorsal portion of the hippocampus and overlying cortex in all hippocampally damaged Ss. The ventral portion of the hippocampus was spared in each case. The amount of cortex removed in the cortically damaged group was somewhat less (approximately $15 \%$ ) than that removed during hippocampal operations. Thalamic degeneration, primarily involving the lateral geniculate nucleus, was observed in a number of Ss in both the hippocampal and cortical groups. The damage was small in all cases and probably indicative of injury to the visual radiations and/or the striate cortex. Representative reconstructions of the lesions are shown in Fig. 1.

The apparatus was an automated two-way shuttle-box, $36 \times 6 \frac{1}{12} \times 10$ in., containing two shock grids. The UCS was a 3 -sec shock from a Model E6070B Grason-Stadler shock generator with scrambler; shock intensity was set at $1 \mathrm{~mA}$. The CS was illumination from a 100-W bulb positioned directly above the center of the shuttle-box. The CS-UCS interval was $10 \mathrm{sec}$. The intertrial intervals were 75,90 , or $105 \mathrm{sec}$, randomly varied. Ss could avoid the shock by moving to the opposite end of the shuttle-box during the 10-sec CS-UCS interval. If this response was made, the CS was terminated immediately and shock was withheld.
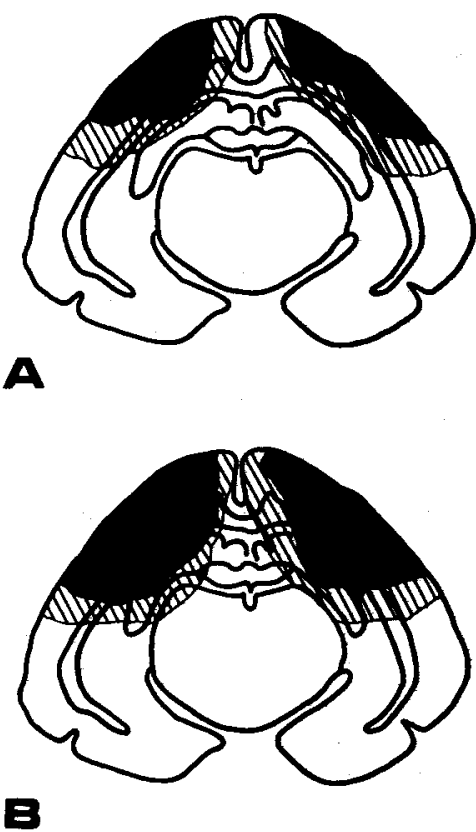

Fig. 1. Reconstruction of the maximum (striped area) and minimum (shaded area) damage sustained by cortical Ss (A) and hippocampal Ss (B) at one level of the lesioned areas.

All Ss received 25 training trials per day for six consecutive days. Training sessions were spaced $24 \mathrm{~h}$ apart. This particular training procedure was expected to produce very little learning of the avoidance response in normal Ss (Evonic \& Brimer, 1967; Webster \& Rabedau, 1964; Webster, Brimer, \& Evonic, 1965). An Esterline Angus event recorder was used to record avoidance responses, spontaneous crossing, and response latency. A learning criterion of nine avoidance responses in 10 trials was employed.

\section{RESULTS}

The number of trials necessary for each $S$ to achieve the learning criterion is shown in Fig. 2. Ss with hippocampal lesions clearly reached criterion more rapidly than either normal or cortical control animals.

An analysis of variance was performed on the response latency data. The difference between groups was significant

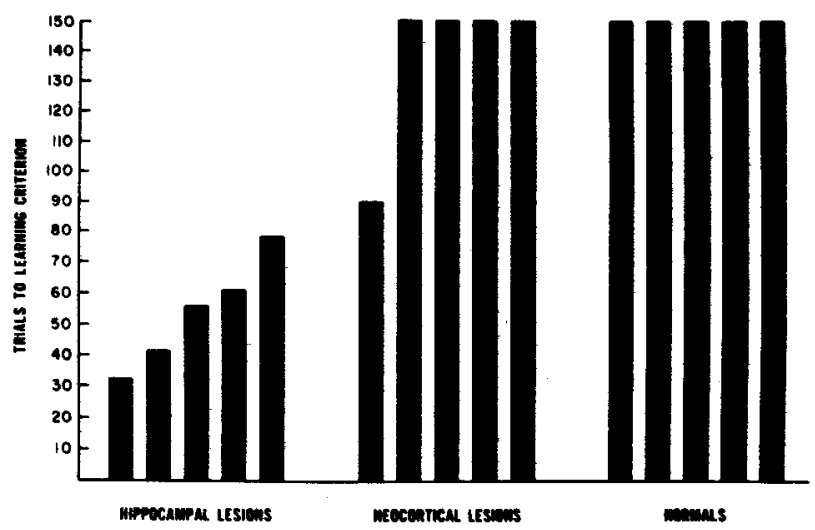

Fig. 2. Trials to learning criterion (nine avoidance responses in $\mathbf{1 0}$ trials) for all groups. 


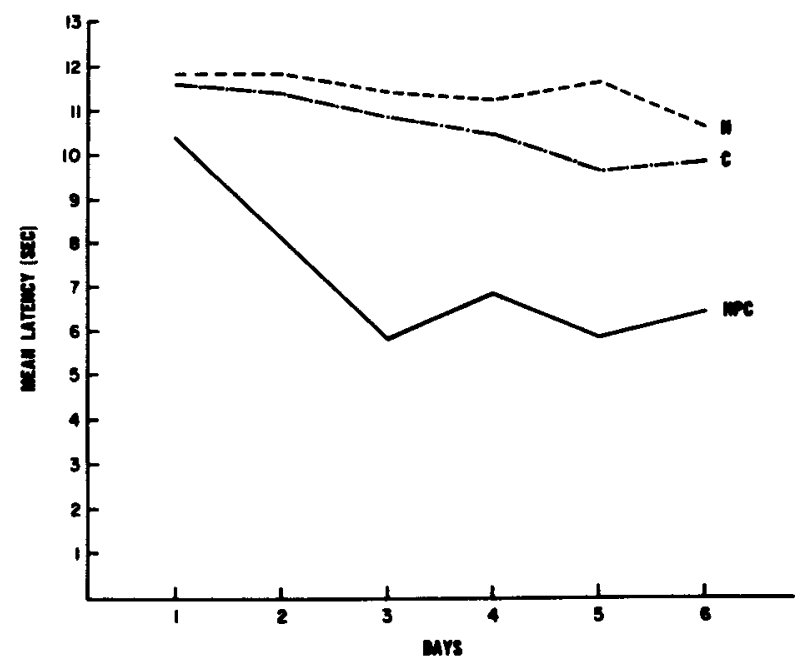

Fig. 3. Mean response latencies for all groups for each day of training.

$(\mathrm{F}=33.40, \mathrm{df}=2 / 12, \mathrm{p}<.001)$, as was the difference within days $(F=9.59$, df $=5 / 60, p<.005)$ and the Groups by Days interaction $(F=4.31, \mathrm{df}=10 / 60, \mathrm{p}<.005)$.

Individual comparisons among pairs of overall group means were performed using Tukey's (1951) multiple comparison method. Hippocampally damaged Ss were found to have significantly lower response latencies than either cortically damaged or normal Ss $(p<.05)$. The cortical group tended to display slightly lower response latencies than the normal group, but this difference was not significant. The nature of the effect across days and the Days by Groups interaction is shown in Fig. 3. The response latencies of the hippocampally damaged group decreased systematically across days while the latencies of the cortical and normal groups were stable over time.

Differences between groups with respect to the number of spontaneous crosses per day were assessed with Mann-Whitney U tests (Siegel, 1956). Hippocampally damaged Ss were found to display significantly more of this intertrial activity than either cortically damaged or normal Ss $(p<.05)$. The cortical group made significantly more spontaneous crosses than the normal group $(\mathrm{p}<.05)$.

Product-moment correlation coefficients were computed between number of spontaneous crosses per $S$, per day, and average response latency per $S$, per day, for each of the three groups. For normals, corticals, and hippocampals, the correlations were $-.79(\mathrm{p}<.10),-.64(\mathrm{p}>.10)$, and -.77 $(p<.10)$, respectively. The consistency of these correlations indicates that $\mathrm{Ss}$ which exhibit a high number of spontaneous crosses will also tend to exhibit low response latencies. DISCUSSION

The results of the present experiment are in agreement with earlier works conducted with rats by Green et al (1967), Isaacson et al (1961), and Olton $\&$ Isaacson (in press). These earlier works and the present study clearly demonstrate a facilitatory effect of large bilateral hippocampal lesions on the performance of a two-way shuttle-box problem. The appearance of this phenomenon in the present study is particularly impressive, considering the normally poor performance displayed by guinea pigs on tasks of this nature (Evonic \& Brimner, 1967; Webster \& Rabedau, 1964; Webster et al, 1965). It may be that this is a general phenomenon in rodents, even those ordinarily unable to learn such tasks.
The present study is also in agreement with earlier work conducted with rats reporting increased intertrial activity in hippocampally damaged and cortically damaged Ss. Isaacson et al (1961) reported that both cortical Ss and Ss with large hippocampal lesions displayed increased spontaneous crossing, although, unlike the present study, no significant difference was found between the two groups. Green et al (1967) reported that although Ss with large bilateral hippocampal lesions showed significantly more intertrial activity, Ss with small hippocampal lesions and cortical Ss were not significantly different from groups of sham operates. In the case of the hippocampally damaged Ss these results are not surprising. Small hippocampal lesions often fail to duplicate the effects produced by more extensive ablation (Douglas, 1967). The results concerning the role of the posterolateral neocortex in the facilitation of intertrial activity, however, are contradictory and remain unclear.

The increased intertrial activity of both hippocampal and cortical $S s$ in the present study may be taken as an indication of a decrease in the freezing behavior normally displayed by guinea pigs on tasks of this nature. Behavioral observation by the authors served to strengthen this impression. Normal Ss were seen to freeze, and in some normal Ss there was a tendency to hide in one corner of the shuttle-box when the CS was turned on. This behavior was rarely seen in cortically damaged $S s$ and never in hippocampal Ss.

The high correlation between intertrial activity and response latency in all three $S$ groups indicates that the increase in intertrial activity is either coincidental with or a cause of the facilitation of avoidance performance. In the case of the guinea pig there are no data available to enable a choice between these two possibilities. The report by Green et al (1967) that small hippocampal lesions in rats, while facilitating avoidance performance, are not accompanied by increased spontaneous crossing, suggests that increased intertrial activity is not necessary for the improvement of avoidance performance. Increased intertrial activity would seem to be a separate effect appearing reliably only in Ss with large hippocampal lesions. More data must be collected, however, before any definitive statement concerning the relationship between increased intertrial activity and improved active avoidance performance may be made.

\section{REFERENCES}

DOUGLAS, R. J. The hippocampus and behavior. Psychological Bulletin, $1967,67,416-442$.

EVONIC, I. N., \& BRIMER, C. J. Effect of variable temporal parameters in avoidance conditioning of the guinea pig. Journal of Comparative \& Physiological Psychology, 1967, 63, 536-538.

GREEN, R. H., BEATTY, W. W., \& SCHWARTZBAUM, J. $S$. Comparative effects of septo-hippocampal and caudate lesions on avoidance behavior in rats. Journal of Comparative \& Physiological Psychology, 1967, 64, 444-452.

ISAACSON, R. L., DOUGLAS, R. J., \& MOORE, R. Y. The effect of radical hippocampal ablation on acquisition of avoidance response. Journal of Comparative \& Physiological Psychology, 1961, 54, 625-628.

OLTON, D. S., \& ISAACSON, R. L. Hippocampal lesions and active avoidance. Physiology \& Behavior, in press.

SIEGEL, S. Nonparametric methods for the behavioral sciences. New York: McGraw-Hill, 1956.

TUKEY, J. W. Quick and dirty methods in statistics: Part 2. Simple analyses for standard designs. Proceedings of the Fifth Annual Convention of the American Society for Quality Control, 1951, 189-197.

WEBSTER, C. D., \& RABEDAU, R. G. The effect of intersession interval in shuttle-box conditioning of the guinea-pig. Psychonomic Science, 1964, 1, 73-74.

WEBSTER, C. D., BRIMER, C. J., \& EVONIC, I. Factors affecting intersession facilitation of avoidance learning in guinea pigs. Psychonomic Science, 1965, 3, 291-292.

$$
\text { NOTES }
$$

1. This research was partially supported by Grant NB-05-001 from the National Institutes of Health.

2. Now at the University of Calgary, Alberta, Canada.

3. The authors wish to thank Dr. Kenneth H. Kurtz who read and aided in the correction of the manuscript and Miss Emily Aleyner who aided in the preparation of the data. 